\title{
An Eco-translatological Perspective to Translator: A Case Study of Xu Chi
}

\author{
Aihua Liu \\ Qufu Normal University, Rizhao, China \\ Email: emmalah@163.com
}

\begin{abstract}
Xu Chi is a writer and translator. He is known as a poet, essayist and "Father of Reportage" in China. In over sixties years, Xu Chi created a large volume of poems, essays, reportages, etc. and translated many foreign literary works into Chinese. An eco-translatological perspective to literary translator criticism emphasizes translator's subjectivity with "translator-centeredness". Xu Chi adapts to the demands of Translational Eco-environment and make selective adaptations and adaptive selections in linguistic, cultural and communicative dimensions. He translates with the pursuit of "doing things with translations" and integrates creation, criticism and translation. A comparatively high degree of selections and adaptations makes his translations well accepted and help to achieve "survival of the fittest".
\end{abstract}

Index Terms - eco-translatological perspective, $\mathrm{Xu} \mathrm{Chi}$, translational eco-environment, adaptive selection, selective adaptation

\section{INTRODUCTION}

$\mathrm{Xu}$ Chi presents to the world about 500 creations under his name. This fruitful writer started his literary career in 1932 when he was just 18 years old. He is firstly a poet, with poems taking the biggest part in his creations; he is an essayist, since he stepped into the Chinese literary world with an essay and produced a large volume of essays; he is entitled as "Father of Reportage" in China, for he integrated factual report with a poetic air to lend a lyric style to his reportages, with At the Foot of Qinlian Mountain (1962), Glory of Geology(1977) and Goldbach Conjecture (1978) as representative. His contributions to the contemporary Chinese literature are well recognized.

$\mathrm{Xu} \mathrm{Chi}$ is also a translator. Besides his large stock of literary creation, he has also produced a large amount of translations. In a time of cultural collision and ideological innovation of the Chinese society from 1930s to 1980s, he chose/selected and introduced into China many foreign literary works, over 60 in fact, among which the Chinese translation of Walden is the most wildly accepted. An eco-translatological perspective to $\mathrm{Xu}$ Chi as a translator will probe into his literary translating practice and thoughts. His translating thoughts, translating strategies, translating purpose and translation achievements will be analyzed to cast lights on the selections and adaptations he has made in translation.

\section{ECO-TRANSLATOLOGY AND LITERARY TRANSLATOR CRITICISM}

Eco-translatology, as has been argued by Chinese scholar Hu Gengshen(2003; 2004; 2008), approaches translation as a process of the translator's adaptations and selections. It proposes that the focal research concern should be given to translator's subjectivity in both adapting to translating requirements and selecting/choosing translating strategies or concrete linguistic expressions from the translational eco-environment. The eco-translatological perspective to translation has illuminated the keynote status of translator in its substantial argumentation of "translator-centeredness" (Hu, 2004, p.83-100). The explicit announcement of "translator-centeredness" has pushed the status of translator to a new height.

On the other hand, the creativity of literary writers and diversity of variables in the field of literary translation leave less possibility for exact predictions. It's those literary translators who have more say in decision-making, in choosing to follow or neglect the requirements or which part(s) of the requirements in linguistic, cultural or communicative dimension. Of course, not only literary translations require the action of translator subjectivity. Literary and non-literary translations differ, or to be exact, every text differs, just in degrees of decision-making possibility. But there is no denying that literary translators enjoy more subjectivity privilege in that they are confronted with more to select/choose from and adapt to, and thus be restricted by. These complicate the case and explain the very reason why literary translators have long been attracting more attention from the translation critics than translators of other fields.

The emphasis of "translator-centeredness" on the translator's subjectivity overlaps with the call for creativity on the part of literary translators, such as the proposal of "creative treason"(Xie, 1999, p.130-143), in that literary translation depends more on the work of literary translators to adjust between, to select/choose among and to adapt to all the factors involved. Moreover, Eco-translatology researchers' explanation and evaluation of translating practice from linguistic, cultural and communicative dimensions are comparatively comprehensive and objective. Hence, the author believes that 
eco-translatology is eligible to serve as a theoretical framework which years of literary translator criticism endeavor can base upon. The present article is to apply this framework to the translating practice and thoughts of Xu Chi, a writer and translator in China.

\section{ADAPTATIONS AND SELECTIONS OF XU CHI AS A TRANSLATOR}

According to Eco-translatology, translation is "a selection activity of the translator's adaptation to fit the Translational Eco-environment" (Hu, 2003, p.268). With Translational Eco-environment, we mean "the worlds of the source text and the source and target languages, comprising the linguistic, communicative, cultural, and social aspects of translating, as well as the author, client, and readers"(Hu, 2003, p.284). For Eco-translatology, the process of translating starts with the Translational Eco-environment "selecting" the translator (Hu, 2003, p.268).

\section{A. The "Selection" of Xu Chi by Translational Eco-environment}

$\mathrm{Xu}$ Chi gets most of his schooling in missionary schools. He had studied successively in the Attached Middle School of Guanghua University, the Attached Middle School of Soochow University, Soochow University and Yanching University. Direct communication with the foreign teachers and much exposure to the English language, literature and culture nurtured him in language proficiency, literary quality and cross-culture ability. He had been the translator for dispatches of foreign news agencies, and the English editor for Chinese Writers and People's China, which can serve as proofs of his superior language proficiency and literary quality. With the large volume of publications and an indisputable reputation in the Chinese literary circle, no one will doubt about $\mathrm{Xu}$ Chi's talent in his native language and literature. His bilingual proficiency and literary quality equipped him with the fundamental condition to be a translator and make him prepared for the "selection" of Translational Eco-environment. These qualities paved the way for Xu Chi to meet the demands of a certain Translational Eco-environment. In other words, that makes it possible for the Translational Eco-environment to "select" Xu Chi as a translator for a certain source text.

Besides, if a "source text is a Shakespearean sonnet", "the Translational Eco-environment is most likely to select a translator who is a poet or a person with strong credentials as a translator of poetry" (Hu, 2003, p.285). In this case, what will the ecological perspective to the statistics in table 1 below tell us then?

TABLE 1

NUMERICAL STATEMENT ON GENRES OF XU CHI's PRODUCTIONS (1932-1983)

\begin{tabular}{|c|c|c|c|c|c|c|c|c|}
\hline & poetry & novel & essay & thesis & reportage & feature & comment & others \\
\hline creations & 163 & 20 & 87 & 36 & 13 & 51 & 41 & 72 \\
\hline translations & 27 & 10 & 6 & 4 & 4 & 4 & 3 & 7 \\
\hline *Statistics come from three sources: Wang Fengbo \& Sun Luqian(1985), Deng Weizhi(2009) and Xu Chi (2007);
\end{tabular}

"Others" covers drama, songs, prefaces/epilogues and speeches, etc.

$\mathrm{Xu}$ Chi is firstly a poet and thus he is selected by the translational eco-environment as a poem translator more often; he is a versatile writer and thus he is selected to be translator of a diversified genre scale.

\section{B. Multi-dimensional Selective Adaptations and Adaptive Selections of Xu Chi}

Within the theoretical framework of eco-translatology, "the process of translating is the production of target texts by 'natural' selection that is made possible by the translator's adaptation to the specific eco-environment, the selection of the degree of the adaptation (selective adaptation), as well as decision-making (adaptive selection) concerning the form of the final target text in terms of natural selection"(Hu, 2003, p.284). The translator's selections of source texts, translating strategy(ies) and translating criteria are results of selective adaptations and adaptive selections to the specific Translational Eco-environments.

The process of Translational Eco-environment's selecting a translator is, on the translator's part, also the process of the translator's adapting to the demands of the Translational Eco-environment and selection of a source text to translate. As has been indicated by table 1 , he selected poems more often to translate than texts from the other genres, and poetry is the favorite genre for $\mathrm{Xu} \mathrm{Chi}$ in both his creation and translation. Xu Chi made selective adaptations to accept the selection of Translational Eco-environment in pre-translation phase.

In terms of translating strategies, a distinct inclination for literal translation is perceived with a scanning of Xu Chi's earlier translations, and in later translations, the translator turned more flexible to integrate literal and free translation together. For example, cultural elements are translated literally with explicative notes in all the translations of Walden; while words or sentences with unusual order prevail in the 1949 version only, following almost slavishly the original syntactic structures, and in the 1982 and 1993 versions, sentences are much smoother and compliant to the Chinese grammar.

In My Literary Career, Xu Chi wrote that literature, in essence, a kind of refine pleasure, and literary translation, unlike the translation of scientific texts, is valued not for exact faithfulness or similarity in form but for similarity in spirit (Xu, 2007, p.468). This viewpoint comes down in a continuous line with that of Fu Lei. Xu Chi went further by realigning the tree-character criteria of Yan Fu in a comparative order with "elegance, expressiveness and faithfulness". 
In eco-translatological terminology, $\mathrm{Xu} \mathrm{Chi}$ made selective adaptations in the linguistic domain and adaptively selected literal translation and then a more flexible strategy to convey the original thoughts and foreign culture. He entrust adaptive selections in the cultural and communicative dimensions with priority to those in the linguistic dimension.

\section{IV. "DOING THINGS WITH TRANSLATIONS" AND "SURVIVAL OF THE FITTEST"}

The eco-translatologists hold that the translating practice of translator should have a purpose_- "doing things with translations" (Hu, 2004, p.10), which echoes the basic argument of functionalism that translation is a purposeful activity. All the translating endeavors are results of Xu Chi's pursuit for "doing things with translations".

$\mathrm{Xu}$ Chi's translating practice originates firstly from his awareness of the demands of Chinese literature to learn from foreign literature. He holds the point that translation is the best way to learn from the foreign world (Xu, 1985, p.54) and the Chinese writers should assimilate the foreign literary works for reference (Xu, 1985: 259). Thus he translated many literary works and wrote articles of criticism on them to help understanding and evaluation. He himself borrowed a lot from the foreign literature: his earlier poems show a Modernist color following Lindsay (Gu, 2006, p.153); and his essays assimilate the succinct style of Hemingway (Xu, 2007, p.174).

Acute for the input discrepancy between nations and the lack of American literature in the 1940s China, Xu Chi pointed out that the majority of the translation endeavor had gone to Russian works, especially those of Evan $S$ Turgener (1818-1883), while much less had been done in introducing American writers (Xu, 1946, p.19). That's why he introduced Pearl Sel, Vachel Lindsay, Ernest Hemingway, Walt Whitman and Henry D. Thoreau, etc. to the Chinese readers. To express his own expectation for victory and to stimulate the public, Xu Chi translated many warfare works in 1940s. His translating of Walden aims at both reference of writing and popularization of Thoreau's thoughts.

A translation will survive if it fits the Translational Eco-environment, and the fittest will survive for the longest. Xu Chi creates, translates and criticizes literary works, which allows him reach nearer to the connotations of a source text. The selective adaptations and adaptive selections he made in linguistic, cultural and communicative dimensions render his translation a comparatively high degree of holistic adaptation and selection.

His translation of Shelly's poems, published in 1943 as a selected poetry anthology named Tomorrow, is deemed to be an outstanding work; his Selected Translations of Iliad in Chinese poetic form is regarded as a great achievement (Ye, 2006, p.62). Among his 65 translations, that of Walden is the fittest to the multi-dimensional Translational Eco-environment and enjoys the widest acceptance. With a total circulation of over one hundred thousand and a enlarging readership, Xu Chi's translation of Walden, we can boldly declare, has achieved "survival of the fittest" to outlive the translations of other translators.

\section{CONCLUSION}

$\mathrm{Xu} \mathrm{Chi}$ as a translator incorporates his creation to analyze his translating practice and thoughts. It tells that Xu Chi chooses the foreign works with his own requirements: demands from the translator's psychological eco-environment ranks as the first to satisfy. The analysis also tells that Xu Chi's versions are fruits of adaptive selections by the translator with an aim to selectively adapt to the dynamic and multi-level translational eco-environments, which makes his translations well accepted.

\section{REFERENCES}

[1] Baym, Nina. (1965). Thoreau's View of Science. Journal of the History of Ideas 26.2, 221-234.

[2] Deng, Weizhi. (2009). Xu Chi Forever. Shanghai: Shanghai Far Eastern Publications.

[3] Feng, Yidai. (2009). Falling of a Shining Star-Lament for Xu Chi. In Deng Weizhi(eds.). Xu Chi Forever. Shanghai: Shanghai Far Eastern Publications.

[4] Gu, Qingyuan. (2006). Xu Chi and Modernism. Foreign Literature Studies 4, 152-159.

[5] Hu, Gengshen. (2003). Translation as Adaptation and Selection. Perspectives: Studies in Translatology 4, $283-291$.

[6] Hu, Gengshen. (2004). An Approach to Translation as Adaptation and Selection. Wuhan: Hubei Education Publishing.

[7] Hu, Gengshen. (2008). Understanding Translation as Adaptation and Selection through the Terms. Shanghai Journal of Translators 2, 1-5.

[8] Sang, Zhe. (2006). Probing into the Chinese Language Planning after 1949. Modern Chinese 11, 27-37.

[9] Thoreau, H. D. (1949). Wa'erdenghu. Xu, Chi (Tr.). Shanghai: Shanghai Chenguang Publishing.

[10] Thoreau, H. D. (1971). Walden. Princeton \& New Jersey: Princeton University Press.

[11] Thoreau, H. D. (1982 \& 1993). Wa'erdenghu. Xu, Chi (Tr.). Shanghai: Shanghai Translation Publishing House.

[12] Wang, Fengbo \& Sun, Luqian. (1985). Collection of Research Papers on Xu Chi. Hangzhou: Zhejiang Arts Press.

[13] Xie, Tianzhen. (1999). Medio-translatology. Shanghai: Shanghai Foreign Language Education Press.

[14] Xu, Chi. (1946). About American Literature. Literary Federation 3, 19.

[15] Xu, Chi. (1985). Foreign Literature and Me. In Wang, Fengbo \& Sun, Luqian(eds.), A Collection of Research Papers on Xu Chi. Hangzhou: Zhejiang Arts Press.

[16] Xu, Chi. (2007). My Literary Career. Tianjin: Baihua Arts Press.

[17] Yao, Junwei. (2005). Xu Chi and His Translation and Introduction of American Literature in China. Foreign Literature Studies, 4, 145-149. 
[18] Ye, Jiaxin. (2006). Maiden Translation Collection of Xu Chi- Tomorrow. Publication Archives 1, 61-63.

Aihua Liu was born in Lin Yi, China in 1975. She received her MA in Linguistics from Qufu Normal University, China in 2002, and is now reading for her PHD in Translation Studies in Shandong University.

She is currently a lecturer in the School of Translation and Interpretation, Qufu Normal University, Rizhao, China. Her research interests include translation studies and eco-translatology. 